\title{
The Position of Marsha Norman's Female Characters from the Perspective of the Socialist-Feminist Ideology ${ }^{i}$
}

\author{
Yasemin Güniz Sertel
}

Department of American Culture and Literature, Faculty of Letters, Istanbul University, Turkey

Copyright $\bigcirc 2017$ by authors, all rights reserved. Authors agree that this article remains permanently open access under the terms of the Creative Commons Attribution License 4.0 International License

\begin{abstract}
Socialist-feminism discusses the subordination and victimization of women in relation with men, the capitalist structure of the society, its institutions, the hegemonic patriarchal culture and history. Marsha Norman as a contemporary American feminist playwright portrays the position of women as victims of the societies they live in her plays. This study aims not to analyze Marsha Norman's plays in a detailed manner, but the purpose of this work is to give an introductory knowledge about Norman's female characters in her plays Third and Oak, Loving Daniel Boone, Sarah and Abraham and Circus Valentine by discussing their oppression in relation with the historical, cultural and social perspectives which are the main points of discussion in the Socialist-Feminist Theory.
\end{abstract}

Keywords Socialist-Feminism, Capitalism, Male Domination, Female Subjugation, Marsha Norman

\section{Introduction}

Marsha Norman, a contemporary American feminist playwright writes her plays with a view to determining the extent of the autonomy women have acquired in American society. This autonomy which is a woman's right to shape and define the borders of her life according to her own desires and requirements is in close relationship with the end of her oppression and the achievement of her liberation in the patriarchal societies. However, this achievement becomes utopic since patriarchal domination can be eliminated only through a revolutionary transformation of every aspect of contemporary societies. In other words, this transformation includes not only the relationship between men and women, but all the social relations which are the main argument of the socialist-feminist theory.

In one of the interviews made with her, Marsha Norman has related women's writing to women's desire to declare their autonomy. As she suggests, "the appearance of significant women dramatists in significant numbers is a real reflection of a change in women's attitudes toward themselves. It is a sudden understanding that they can be, and indeed are, the central characters in their own lives."[1] As a matter of fact, Suffrage Movement has been a turning point for women to acquire their autonomies in history since this movement has also initiated women's liberation as a political mass movement. Yet, in spite of these movements which seemed to have changed the social status of women in the family, at the work-place and in the society at large, it would be a total illusion to suggest that women think, act and behave completely autonomously and they are, as Marsha Norman claims, "the central characters in their own lives." This is because in capitalist patriarchal societies women are preyed, silenced and victimized by all the institutions of the society which are totally governed by patriarchal norms. However, since patriarchy appears as a specific form of male dominance, the basis of women's oppression stems from men's perspective and treatment of women. It is indeed this masculinist approach that defines and determines the position of women in historical, cultural and social mechanisms. Contrary to what Marsha Norman declares in her interview, the plays that constitute this study reveal the historical, cultural and social elements as significantly influential in causing both the roots of women's oppression and also the continuation of their subordination, even today. In addition, throughout these plays, it is suggested that revealing the roots of women's oppression involves the circumstances and institutions that must be wholly changed in order to actualize women's capacity to act and choose, that is, their autonomy. This perspective is also what socialist-feminist theory declares as an ideology.

In general, feminist movement deals with the subordination and victimization of women as members of an oppressed class. Especially Women's Movement in 1960s helped women to discuss their problems on a larger scale; thus, it was comprehended that the source of women's problems was not their inability to adopt themselves in life but that they were embedded in the basic structures of the society. This realization led to the resolution that women's 
problems necessiated significant changes in the society. Although there are endless discussions about the origins of women's oppressions, it would not be sufficient and satisfactory to consider the origins of this oppression only from a historical perspective. There are, in addition, social, biological and psychological factors which are significantly influential in causing the permanency of women's subordination. Actually, women's autonomous position in the society is not only reflected to the realization of her oppression with the cited factors, but also the revolutionary change that should be actualized in the basic institutions of the society. This condition requires an analysis of the relations between women and the social institutions. And socialist-feminism observes and defines women's relationship with these basic social institutions in question.

\section{Marsha Norman's Woman Characters and the Socialist-Feminist Ideology}

In Marsha Norman's plays Third and Oak, Loving Daniel Boone, Sarah and Abraham and Circus Valentine, there is an implicit message of the socialist-feminist ideology that a revolutionary change should occur in patriarchal societies for the liberation of women and the first step of this liberation lies in the destruction of capitalism. Throughout these plays, even though women take place on the different echelons of a class society, they are all united by the oppression they suffer as women and they cannot achieve a full liberation without getting rid of the policies of the capitalist system. Marsha Norman's play Third and Oak consists of two one-act plays; The Laundromat and The Pool-Hall. As a matter of fact, these two one act plays complete each other, one reflecting the encounter of two women in a laundromat, the other of two men in a pool-hall. The Laundromat is about a brief encounter between two strangers, Deedee and Alberta, both doing their laundry at 3 a.m. while learning something about each other during their conversation. The Pool-Hall on the other hand, focuses on Shooter's relationship with Willie, the owner of the place. In Third and Oak, the socialist-feminist assertion that the liberation of women lies in the destruction of the capitalist system is illustrated in the victimization of three different woman characters, Alberta and Dedee in The Laundromat part and Sondra in The Pool-Hall part, who belong to different classes and thus who lead different kinds of life. Their socio-economic positions also create unreachable gaps among them in the social strata. However, what unites these heroines is their oppression due to their dependency on the male power. Loving Daniel Boone focuses on the dreams and experiences of Flo (Florence), a cleaning woman in a history museum who has fallen in love with the mythical character Daniel Boone and thus, who time-travels to the past to help save Boone when he is captured by the Indians and then returns to the contemporary society.
Therefore, In Loving Daniel Boone, the predicament of Flo is depicted, whose unhappiness and dissatisfaction stem from the unpleasant circumstances and opportunities that the capitalist system offers to its laborers, which also leads her to search for some alternative life styles in history. Sarah and Abraham also reflects the oppression of women by the patriarchal institutions of the society reflected as marriage, family, religion or profit-making motive of the capitalist system both in the past and in the present. The play gives the story of a group of company actors who try to act out the biblical story of Sarah and Abraham. Weaving the personal lives of these actors and actresses into the biblical lives of Sarah and Abraham, Marsha Norman creates a mythical correspondence with the contemporary characters. And Circus Valentine involves the struggles of a group of individuals working in a circus and trying to reinforce an unsuccessful company while at the same time endeavouring to preserve their human values and dignity. In Circus Valentine, the suffering of women is closely related not only to their fate of womanhood and the victimization of the working class they belong to, but also to the oppression of ethnic and minority group people.

The ideologies of the socialist-feminist theory become functional in the consideration of these plays, because when the needs of women are considered from a class perspective, it is obviously seen that their liberation is also related to other people's being saved and freed from the exploitation and manipulation of the dominant class. In other words, the struggle of women is parallel to the struggle of the working class within a capitalist system creating discriminations between male, female, ethnic and minority group workers as well as poverty and diminishing the value of personal work in a technological society. Therefore, people must unite in their struggle against capitalism and work together in order to challenge that system and its institutions. As a matter of fact, this perspective defines the goal of the socialist-feminism since this movement "moves beyond an attempt to create equality of women within the system to a struggle for equality within a new system that is not dependent on male domination or any exploitation of one group by another." [2] Therefore, to actualize "the elimination of sex roles" and to gain their autonomy, "women [...] must work along with other oppressed groups." [3] In Circus Valentine, Goldie, who is the embodiment of a working class, ethnic and minority group, is reflected as a totally dissatisfied woman who has lost her faith in her work, her husband and life in general, and hence feels lost. However, her unpleasant situation is closely related to the situation of the other people who work in the same circus and thus share the same house, work and fate with her. The reason for her unhappiness as a woman lies in the destiny of the people she works with, and thus identifying Goldie with the working class actually results in interpreting women's oppression as an aspect of class oppression. The oppression of these people is caused by the capitalist system, which is represented in the identity of a capitalist boss Reeves, who, 
exploits his workers' labor power; the great amount of profit he makes is the outcome of his policy of paying the circus people, his laborers, less than the value of what they produce and taking from them their tent - which is both their home and workplace-, with total disregard of their predicament. Therefore, while this policy brings wealth to him, it creates poverty, unemployment and distress to the circus people and hence victimizes them.

\section{The Predicament of Women in Marsha Norman's Plays as a Result of The Relationship between Capitalism and Patriarchy}

Throughout these plays, Marsha Norman also emphasizes the significance of the relationship between capitalism and patriarchy by revealing how her women characters' experiences are determined by this relationship. Since the capitalist society is represented as a system of class domination in the plays, patriarchy determines the rules of male dominancy over Norman's women because, as Heide Hartman suggests, "the original and basic class division is between the sexes, and the motive force of history is the striving of men for power and domination over women, the dialectic of sex."[4] While patriarchy functions as institutionalized male control over Norman's women both within the home and work-place, capitalism brings sexual division of labor as a form of manipulation of women. As a matter of fact, patriarchy defines and determines these women's inferior economic and social statues by a sexual division of labor, in which men and women have different responsibilities. As Heidi Hartman suggests; "The material base upon which patriarchy rests lies most fundamentally in men's control over womens' labor power. Men maintain this control by excluding women from access to some essential productive resources (in capitalist societies, for example, jobs that pay living wages) and by restricting women's sexuality. Monogamous heterosexual marriage is one relatively recent and efficient form that seems to allow men to control both these areas" [5] Hence, Joe in the first act of Third and Oak and Fred in Circus Valentine exert their power on and enforce their control over their wives Dedee and Goldie as the heads of their families who make money in the public place, whereas Dedee, as a housewife, and Goldie, as a mother, are obliged to obey their bread-winning husbands.

\subsection{The Position of Marsha Norman's Women in the Sexual Division of Labor}

On the other hand, the sexual division of labor as the material base of patriarchy in the world of Marsha Norman's plays comes to the foreground in Fred's control over his wife's labor power and hence Goldie's separation from her job of trapeze flying after marrying him in Circus Valentine.
And for fear of her husband's controlling power over herself, Dedee in The Laundromat hides from him the fact that she is working in a part-time job in a company, writing names and addresses on their letters. Hence both Fred's and Joe's controlling powers are revealed through their denial of Deedee and Goldie access to economic resources, which results in the women's dependence on them and maintains the places assigned to their wives and themselves by the capitalist patriarchal society. In this arrangement, which perpetuates the husbands' material advantage over their wives, both Joe and Fred encourage their wives to stay at home as housewives, and, in case of Goldie, rear children. As a result of the sexual division of labor, the lower status of work is reserved for women characters in these plays. This is why in Loving Daniel Boone Flo works as a cleaner, in Circus Valentine Goldie works as a cook, and in The Laundromat Deedee works as an address writer on envelopes, which is hidden from her husband as a further extension of her oppression. By working in these jobs, these women at the same time become a reserve labor force in the capitalist system and are perceived not only as lower waged workers but also as house-keepers, and thus, on the larger scale, provide extra profit to their employers, which also intensifies their oppression and victimization in capitalist patriarchal societies.

\subsection{The Position of Marsha Norman's Women in the Sex- Gender System}

Throughout these plays, the place of Marsha Norman's characters in the sex-gender system also functions to perpetuate patriarchy or male dominance, as well as capitalism. In 'The Traffic in Women', Gayle Rubin explains the sex-gender system in capitalist societies as follows: "Every society has some form of organized economic activity. Sex is sex, but what counts as sex is equally culturally determined and obtained. Every society also has a sex-gender system - a set of arrangements by which the biological raw material of human sex and procreation is shaped by human, social intervention and satisfied in a conventional manner, no matter how bizarre some of the conventions may be." [6] Therefore, the design of the sex-gender system creates such a structure that the choices, tasks, and interests of women conflict with those of men. "As men took over most of the activities of social production, and with the rise of the family institution, women became relegated to the home to serve their husbands and families. The state apparatus came into existence to fortify and legalize the institutions of private property, male dominion and the father-family which later were sanctified by religion."[7] Hence, in this structure women are obliged primarily to feel responsible for the private-service sphere duties of housework and child-rearing, whereas men are gendered to take place in the public sphere and are obliged to earn a living and support their families materially. This situation gives Joe the 
position of supremacy in The Laundromat, as he is the bread-winner and supporter for Deedee and results in the assignment to Deedee of the position of nurturer and server of Joe in personal and sexual ways. And Flo's choice of marrying Hilly and her decision not to work anymore but be a housewife at the end of Loving Daniel Boone is also her internalization of her sex-gender role as a woman. However, the society in which she lives does not offer her any better alternatives. On the other hand, Monica/Hagar's position in Sarah and Abraham is representative of women's role as sexual servers in the private-service sphere and in the market place.

On the other hand, among the private-service sphere duties determined by the norms of the sex-gender system, women are assigned the responsibility of looking after children, which results in "perpetuating patriarchy as a system." [8] This position of women is what Goldie experiences in Circus Valentine when she leaves her job in order to maintain her mothering task of looking after her daughter, Trina. Yet, by doing so she has accepted her subjugation to her husband Fred. In the second act of Third and Oak, the demand of the patriarchal figures from Sondra to give birth is also their expectation appropriate to the sex-gender roles of femininity. In the biblical play of Sarah and Abraham, the main theme revolves around the task of child-rearing, both for Sarah and Hagar, without ever questioning their gender roles as mothers. Besides the biblical play, even in the frame play, Kitty/Sarah's choice of wishfully leaving her career in order to look after her soon-to-be-born baby is also her acceptance of the sex-gender role of being a mother.

\section{Women's Victimization in the Institutions of Marriage and Family}

As a matter of fact, the institutions of marriage and family in these plays become the primary units of the sex-gender system which reproduce concrete forms of socially organized sexuality. Both the institutions of the traditional nuclear family unit and monogamous heterosexual marriage are reflected as producing personality types suitable to the gender discrimination of the economic system. In these institutions the male partner is representative of his family in the external world, whereas the female partner represents the socio-economic position of her husband in the society, even if she works or has a respectable social status. Such position of women in these institutions also reveals their domestic enslavement in the private-service sphere. As a matter of fact, this enslaved position of women has its roots in monogamy: "It is the existence of slavery side by side with monogamy, the presence of young, beautiful slaves belonging unreservedly to the man, that stamps monogamy from the very beginning with its specific character of monogamy for the woman only, but not for the man. And that is the character it still has today." [9] This is why Deedee is oppressed in her relationship with Joe and this is why she has to stay at home and helplessly wait for her unfaithful husband even though she has a part-time job and thus an income in Third and Oak. On the other hand, for the same reason Alberta in the same play cannot get rid of the memories of her dead husband Herb although she is a retired teacher who has a respectable social status as well as a satisfactory income. In Circus Valentine, Goldie, too is deeply oppressed and even victimized by the institution of marriage since she has sacrificed her public life in order to enter the institution of marriage, whereas Flo in Loving Daniel Boone willingly but unawittingly accepts a similar position by deciding to marry Hilly and stop working. Meanwhile in Sarah and Abraham, Sarah's oppression in the biblical play begins with her marriage to Abraham, in which she cannot give him a baby as appropriate to her gender role. She is oppressed even though she is a rich woman with a high status in her community. Although later in the story she gives birth to a son, her oppression does not end since she loses her husband to another woman, Hagar, in spite of her endless sacrifices to him. This play, while portraying male power as the absolute authority in the domestic area, also reveals the consideration of the children as the property of the father as well as being his natural heirs. It is for this reason that Abraham and Sarah makes plans of taking Hagar's baby from her - the baby's father is Abraham and Hagar is Sarah's slave - without ever considering her feelings, which constitutes her oppression as a mother besides her oppression stemming from being a woman. And in the frame play, Kitty/Sarah is again oppressed by her marriage to Cliff/Abraham since she has to tolerate her husband's numerous infidelities even though she is a self-confident and a very successful woman with a bright career.

\section{The Illustration of an Anthropological Approach in the Plays: The Kinship System}

On the other hand, as the family is the basic unit in a society and as families produce gendered identities for the society, the relationship in the family becomes a mirror image of those in the society. In Loving Daniel Boone and Sarah and Abraham, women's oppression in the family setting is emphasized and suggested in its historical and antropological counterpart; the kinship system in which women are exchanged as gifts. In this system, "gift-giving is the expression, affirmation or the creation of a social relationship between the partners of an exchange". [10] In Loving Daniel Boone, Flo is handed over first from chief Blackfish to Boone and then from Boone to Hilly as a wife in the native community to which she has time-traveled. Meanwhile, in the biblical play of Sarah and Abraham, Hagar is presented by his father to Sarah and then by Sarah to Abraham for the very same reason. In both plays women 
are presented as gifts whereas men are receiver of the gifts. And it is these male partners, not the female presents, upon whom "mutual exchange" presents its meaning of social relations. In the relationships of such a system, neither Flo nor Hagar is in a "position to realize the benefits of their own circulation."[11] By presenting Flo, Chief Blackfish prevents a soon-to-appear battle, while at the same time Hagar's exchange prevents her father, the Pharoah, from facing a probable disaster. Therefore, the exchange of women becomes in these plays the expression of the historical and social fact. While the position of women in these plays reveals them as exchanged objects, the male figures become "the beneficiaries of the product of such exchange" in which the ritual itself forms the "social organization." [12] As a matter of fact, "exchange of women" is the expression of the historical and social fact that "the social relations of a kinship system specify that men have certain rights in their female kin, and that women do not have the same rights either to themselves or to their male kin. In this sense, the exchange of women is a profound perception of a system in which women do not have full rights to themselves... [And thus] the subordination of women can be seen as a product of the relationships by which sex and gender are organized and produced". [13]

\section{Marsha Norman's Women and Sexuality}

Another subject Marsha Norman pinpoints throughout her plays is how sexuality/ contemporary sexuality is shaped both by male dominancy and capitalism. In these plays, Marsha Norman's women can be classified into two groups. On the one hand, we have Deedee in The Laundromat, Goldie in Circus Valentine, and both Sarah and Hagar in the biblical play of Sarah and Abraham, whose sexualities are determined and limited by the patriarchal society and its institutions that there is hardly any alternative offered to them. Being deeply bored by her situation, Deedee tries to transcend the boundaries of her sexuality by befriending Shooter in the absence of her husband, yet this time she is hindered and sent home where she belongs to by another male figure, Willie, who represents all the regulatory norms of the patriarchal society in his identity. Thus, Goldie has never found a chance to live her sexuality due to her struggle as a member of the working class, ethnic family and minority group problems. The characters of both Sarah and Hagar are denied sexual lives of their own because of the religious, patriarchal and social norms of the community in which they live. Yet, in spite of her presence in such a community, Hagar exhibits a different and free sexual attitude. Despite all the inhibitions from that community, she cannot repress her sexual feelings towards Abraham, a behavior which cannot be linked to women's liberation, but to Hagar's otherness, that is, her coming from the pagan community of Philistines which has different values, conventions and cultural norms from those of the community she lives in now.

\subsection{The New Image of Women in the Plays}

On the other hand, in the contemporary society, a revolutionary transformation seems to occur in the representation of women. This transformation includes the shift in the image of woman from the traditionally submissive, passive and oppressed type into the new rebellious, active, self-reliant one who is represented in the "celebration of Madonna as a post-modern heroine" and "a subversive culture figure" in her challenging attitudes. [14] This revolutionary transformation can be observed in the representations of Flo in Loving Daniel Boone, and Eva in Circus Valentine. Considering them from a sexual perspective, they no more represent the traditional type of woman who is submissive, passive and oppressed. Instead, they have a contemporary, new-rebellious, challenging, active and self-reliant attitude in the matters of sexuality. Both Flo and Eva refuse to allow themselves to be constructed as passive objects of patriarchal desire and want to live their female sexualities independent of patriarchal control. Monica/Hagar in the frame play of Sarah and Abraham, and Sondra in The Pool-Hall represent another type of woman whose sexuality has grown out of the norms of a society organized to make profit and to preserve male privileges. Both Sondra and Monica/Hagar have been victimized by the capitalist society, the norms of which have imposed on them the teaching that the sexual attractiveness of women is dependent on the expanding beauty industry of cosmetics, plastic surgery and a whole range of commodities to be bought. This is evident that Sondra spends a great deal of money in shopping, whereas Monica/Hagar has become a good product of the beauty industry by the influence of the mass media which consciously plays a great part in awakening her to a new reflection of identity shaped by the profit-making intentions of the capitalist society. As a matter of fact, this situation is a proof of the victimization of woman by mass media and advertisements - another profit-making tool of the capitalist machinery. As Sheila Rowbotham suggests, this victimization creates a false image of femininity: "Acting on the assumption that women regard themselves through men's eyes as objects of pleasure, advertising and the media project a haunting and unreal image of womanhood... They are given an ideal of femininity which is foisted onto them by ever more powerful forms of the mass media". [15]

However, the plays also imply that the new sexual freedom and the sexual permissiveness of the contemporary society are in fact illusions. This is illustrated by Flo's decision to abandon the free sexual life she shares with numerous men aside, marry Hilly, and be a housewife to serve him and his daughter at the home in Loving Daniel Boone. Furthermore, Eva, at the end of the play, Circus 
Valentine, confesses to her polar opposite, Goldie, that she envies her. And in the cases of Sondra İn Third and Oak and Monica /Hagar in Sarah and Abraham, it is obviously revealed that a genuine sexual liberation is possible for them only when their sexualities are no longer shaped by the need to generate profits or to perpetuate male supremacy. Only in such a social context can they attain sexual fulfillment that transcends their sexual commodification.

\section{Conclusions}

In all these plays, the oppression and victimization of women are studied from different perspectives, while the roles and functions of their history, culture and social conventions are also emphasized in their predicament. Although each of the plays depicts a different type of woman either from history or from contemporary life, either liberated or enslaved, as a matter of fact, each woman is restricted and suppressed by the powers that shape the patriarchal society she lives in. As long as these women, whose experiences represent the predicament of general women, continue to be governed by the institutions of the same patriarchal capitalist society, they cannot experience real liberation, which also means that they cannot act as definite and complete autonomous identities. Women can think, act and behave in an autonomous way only when they make their own decisions, according not to the regulatory norms of the society, but to the desires of their own personalities and when they are offered real equal opportunities in every context of their cultural, familial, social, economic and work lives.

Throughout these plays, sexual issues are recognized as fundamentally political. However, sexual domination by men is not always the primary source of women's oppression, since the dispute between women and men derives from the economic as well as the sexual foundation of society, and domination can be eliminated only through a revolutionary transformation of every aspect of contemporary society. In other words, this transformation includes not only the relationship between men and women, but all the social relations. This transformation should include not only all the patriarchal institutions of the society, but also the regulatory norms and arrangement of the sex-gender system which preconditions men in their perspective and approach to women. This possibility can be actualized by the endeavors of the whole society. And unless this revolutionary transformation is actualized, the autonomy of women, mentioned in the very beginning, will remain no more than an illusion.

\section{REFERENCES}

[1] S. Burke. American Feminist Playwrights: A Critical History, Twayne Publishers, New York, 1997, 203-204.

[2] A.M. Jaggar \& P.S. Rothenberg. Feminist Frameworks Alternative Theoretical Accounts of the Relations Between Women and Men, McGraw Publishing Company, New York, London, Toronto, 1984, 153.

[3] ibid.153.

[4] H. Hartman. "The Unhappy Marriage of Marxism and Feminism: Towards a More Progressive Union" in The Second Wave - A Reader in Feminist Theory, Ed. By L. Nicholson, Routledge, New York, London, 1997, 100

[5] ibid. 101

[6] G. Rubin. "The Traffic in Women: Notes on the Political Economy of Sex" in The Second Wave - A Reader in Feminist Theory, Ed. By L. Nicholson, Routledge, New York, London, 1997, 32

[7] E. Reed. "Women: Caste, Class or Oppressed Sex" in Feminist Frameworks - Alternative Theoretical Accounts of the Relations Between Women and Men, Ed. by A.M. Jaggar \& P.S. Rothenberg McGraw Publishing Company, New York, London, Toronto, 1984, 133.

[8] H. Hartman. "The Unhappy Marriage of Marxism and Feminism: Towards a More Progressive Union" in The Second Wave - A Reader in Feminist Theory, Ed. By L. Nicholson, Routledge, New York, London, 1997, 101

[9] Engels as cited in A.M. Jaggar \& P.S. Rothenberg. Feminist Frameworks - Alternative Theoretical Accounts of the Relations Between Women and Men, McGraw Publishing Company, New York, London, Toronto, 1984, 129.

[10] G. Rubin. "The Traffic in Women: Notes on the Political Economy of Sex" in The Second Wave - A Reader in Feminist Theory, Ed. By L. Nicholson, Routledge, New York, London, 1997, 35

[11] ibid. 37

[12] ibid. 37.

[13] ibid. 38-39.

[14] S. Bordo. Unbearable Weight: Feminism, Western Culture and the Body, University of California Press, London, 1995, 268.

[15] S. Rowbotham. "Imperialism and Sexuality" in in Feminist Frameworks - Alternative Theoretical Accounts of the Relations Between Women and Men, Ed. by A.M. Jaggar \& P.S. Rothenberg McGraw Publishing Company, New York, London, Toronto, 1984, 423. 